\title{
Experimental Analysis of a Solar Air Dryer with Thermal Energy Storage Unit (PCM)
}

\author{
Virendra V. Bhagwat ${ }^{1}$, Vaibhav P. Patil ${ }^{2}$, Krantikumar K. Bhosale ${ }^{3}$, Sandip P. Kambale ${ }^{4}$ \\ Assistant Professor, Mechanical Department, Dr. Daulatrao Aher College of Engineering, Karad, India 1,2,3,4
}

\begin{abstract}
Among the various renewable energy resources solar energy potential is the highest in the country. The global solar radiation over India varies from 4-7 kWh/sq. m/day. The solar energy is also used for heating the air that air is applied to dry the clothes, food dehydration, natural rubber, etc. Circulation of atmospheric temperature air from solar flat plate collector and then that high temperature air is supplied to room. In India, we have 12 sunshine hours and 12 non-sunshine hours so solar air heater is limited to run only in sunshine hours. To run it night time it required external energy supply, so cost of the solar air heater is increase. Our requirement is to supply the hot air to the room up to $60^{\circ} \mathrm{C}$ to $65^{\circ} \mathrm{C}$ temperatures during day and night time. To achieve such high temperature we need to modified the conventional solar air-dryer in such way that it will gives us hot air temperature in the range of $60{ }^{\circ} \mathrm{C}$ to $65^{\circ} \mathrm{C}$. For the use of Solar Air Dryer during night time, some form of energy storage is required during sunshine hours and that stored energy can be used during non-sunshine hours. Present work is focused towards incorporation of heat pipes with LHTES is of interest. Heat pipes increase heat transfer rates to or from the Phase change material (PCM), while maintaining small temperature differences between the PCM and heat transfer fluid (HTF) in heat pipe. This experimental setup, solar air-dryer assisted with TES unit including PCM and heat pipe. This study focuses on to the performance enhancement of flat plate collector solar air-dryer.
\end{abstract}

Keywords: Heat pipe, solar air-dryer, Phase change material (PCM), TES.

\section{INTRODUCTION}

Solar drying is another very important application of solar energy. Solar dryers use air collectors to collect solar energy. Solar dryers are used primarily by the agricultural industry. The purpose of drying an agricultural product is to reduce its moisture content to a level that prevents its deterioration. In drying, two processes take place: One is a heat transfer to the product using energy from the heating source, and the other is a mass transfer of moisture from the interior of the product to its surface and from the surface to the surrounding air [1].

A very common problem in solar drying and various other industrial processes is the existing gap between the period of thermal energy availability and its period of usage. This situation creates the need for an effective method by which excess heat can be stored for later use. Latent heat thermal energy storage is one of the most efficient ways of storing thermal energy through which the disparity between energy production or availability and consumption can be corrected, thus avoiding wastage and increasing the process efficiency [2].

Thermal energy storage (TES) systems provide a good solution to this issue. Latent heat thermal energy storage (LHTES) systems offer the possibility of storing higher amounts of energy per unit of storage material mass in comparison to sensible heat thermal energy storage (SHTES) systems. However, the performance of most commercially viable phase change materials (PCMs) which used as storage media in the LHTES systems suffer from low thermal conductivity. This often leads to much longer charging or discharging process and significant temperature difference within PCM, which in some cases can cause system overheating and material failure [2].

Currently, three types of TES are being considered for solar power generation and other applications: sensible heat thermal energy storage (SHTES), latent heat thermal energy storage (LHTES), and chemical thermal energy storage (CTES) [3]. Of these, LHTES is of particular interest because it is characterized by high energy density and potentially reduced cost relative to SHTES [4]. LHTES has been researched extensively relative to CTES which is in the developmental phase. However, before large LHTES units are constructed, laboratory scale research should be conducted to verify the potential of LHTES as an effective and inexpensive energy storage option. A barrier to the development of large scale LHTES is the low thermal conductivity of most phase change materials (PCMs) and much of the previous research regarding LHTES has focused on reducing the thermal resistance posed by the PCM. For example, Velraj et al. [5] incorporated Lessing rings within the PCM and observed increased heat transfer rates from the PCM to a coolant, making the technique suitable for reducing solidification times. The investigators also considered use of extended surfaces to increase heat transfer, concluding that fins also reduce total solidification times by approximately $75 \%$ based upon the predictions of a numerical model. Similar results for LHTES melting (charging) experiments utilizing a finned heat transfer 
IARJSET

fluid (HTF) tube have been reported by Balikowski and per the requirement. This technique may be useful to Mollendorf [6]. Sparrow et al. [7] showed that small fins improve performance and efficiency of solar dryer with can triple the amount of PCM that freezes about a cold solar energy storage unit. The solar air dryer with separate tube. In other work, Agyenim et al. [8] demonstrated that solar thermal storage unit with the help of phase change faster PCM heating can be achieved by increasing the material and heat pipe. number of heat transfer tubes embedded in a PCM. Although the preceding approaches increase heat transfer rates in LHTES systems, they all occupy volume within the PCM storage vessel. Ideally, any strategy to increase heat transfer rates would also occupy little space in order to maximize energy storage capacity. In this study, incorporation of heat pipes with LHTES is of interest. Heat pipes may increase heat transfer rates to or from the PCM, while maintaining small temperature differences between the PCM and HTF. Limited research regarding heat pipe-assisted LHTES has been conducted. Faghri holds two US patents that describe the use of miniature heat pipes in small LHTES modules [9].

Experimentally, Lee et al. [11] developed a low temperature LHTES system operating with a variety of PCMs that utilized a two-phase thermo syphon operating with ethyl alcohol as the working fluid. Paraffin LHTES, with copper-water heat pipes embedded within a rectangular PCM enclosure was developed and tested by Liu et al. [12]. Recently, Shabgard et al. modelled a large scale heat pipe-assisted LHTES and reported predictions showing improvement in both melting and solidification rates [13]. Although some research has been conducted regarding heat pipe-assisted LHTES, the effectiveness of the approach has apparently not been quantified experimentally. Therefore, the objective of this study is to experimentally establish the effectiveness of heat pipes in potentially increasing heat transfer rates in a LHTES system by directly comparing measured performance with: (i) a system with no heat pipes, and (ii) a system utilizing fins in lieu of heat pipes. Results are reported for both melting (charging the LHTES system) and solidification (discharging).

\section{DESIGN OF STUDIED SYSTEM}

Experimental investigate and performance enhancement of flat plate collector solar air dryer with selective coating material and thermal energy storage unit. Thermal energy storage unit consists of PCM and heat pipe. The usage of PCM for the storage of energy and that storage energy is used in night time.

The performance and efficiency can be increased by adopting a new arrangement of the solar flat plate collector which will work as solar energy store unit during sunshine hours and energy supply unit during off sunshine hours. During sunshine hours it is isolated with solar dryer and will work as solar energy absorber as well as storage unit. It is connected with solar dryer cabin during off sunshine hours and solar air collector will be disconnected from the cabin. This is one of the separate energy storage unit which can be connected or isolated from the solar dryer as

Heat pipe is a device which transfers heat from a source to sink by alternate evaporation and condensation of fluid inside a sealed system with temperature drop of $5^{\circ} \mathrm{C}$ per meter length of pipe [6]. Heat pipe is a stationary device and also it does not have any moving parts. Heat pipes are dipped in PCM. During day time PCM is melting (charging) and night time PCM starting solidifying (discharging), during discharging it liberate heat. That heat is transfer from one end to another end by using heat pipe. So the drying process is also continued in night time. Our solar dryer is with reflective mirror. At day time reflective mirror is used to reflect solar rays on PCM bed which helps in PCM melting and during night time using reflective mirror we close the PCM bed due to the inclusion of reflective mirror on the PCM bed heat loss to the surrounding is reduces and increases the drying potential considerably.

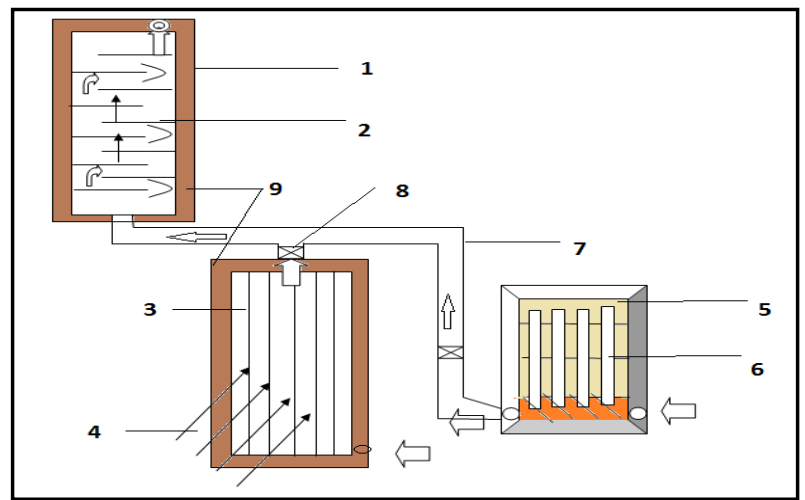

Fig 1: Solar air dryer: (1) Storage, (2) trays, (3) FPC, (4) Solar rays, (5) PCM, (6) Heat pipe, (7) Piping, (8) Control valves, (9) Insulation

\section{A. Methodology:}

During sunshine hours solar air FPC is directly connected to the dryer cabin and thermal energy storage unit is disconnected from the dryer cabin. Instead of hot air from solar air flat plate collector will give the heat to phase change material in PCM thermal storage unit, the heat will be taken directly from solar radiation during sunshine hours. This heat is stored in PCM by changing the phase from solid to liquid (latent heat). At off sunshine hours the solar thermal storage unit is connected to the dryer cabin and solar air flat plate collector will be disconnected by three way valve unit. The air will flow through the thermal energy storage unit and will be heated by taking latent heat of PCM, this hot air then pass through the dryer cabin. To maintain the air flow through the assembly, a draft fan is located at the base of the dryer cabin. To optimize the system for particular operation, we will study various parameters related with this system. 
IARJSET

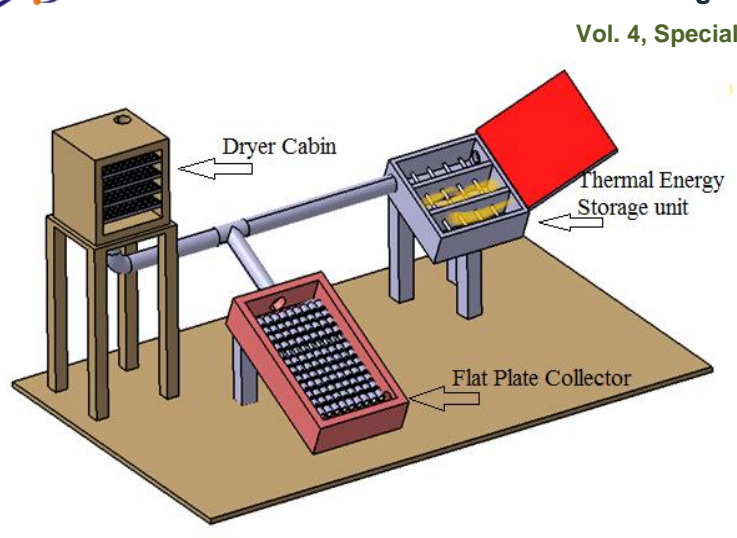

Fig 2: Experimental setup.

These parameters are:

1) Air velocity

2) Day time

3) Phase change material

4) Natural and forced circulation

5) Working fluid in heat pipe

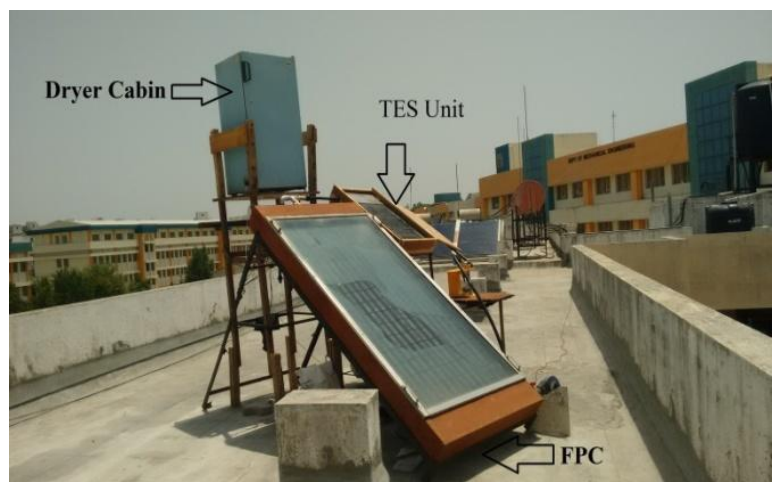

Fig 3: Experimental setup.

\section{B. Flat Plate collector:}

Solar flat plate collector is made up of waste Aluminium cans. In order to reduce cost of raw we use aluminium cans for manufacturing an air collected pipes. Cans having Same $6 \mathrm{~cm}$ diameter and that cans are joined with the help of silicon. From this cans we made a 15 pipes. With the help of silicon we also prevent the air leakages from pipes. We made $2 \times 1 \mathrm{~m}^{2}$ MS (Mild Steel) frame and all this pipe is fitted into the frame Rock wool is placed bottom and side portion of a frame to prevent the heat losses. Black board paint mix with activated charcoal is applied over pipes. Absorptivity of charcoal is very high, so large amount of solar radiation can absorb by panel.

Table no 1: Speciation of FPC.

\begin{tabular}{|l|l|}
\hline Parameter & Specification \\
\hline Dimension of FPC & $2 \mathrm{~m} \mathrm{X} \mathrm{1m}$ \\
\hline Insulation & Rockwool \\
\hline No. of glass used & 2 \\
\hline Absorbing material & Activated charcoal \\
\hline Inclination of FPC & $33.53^{\circ}$ \\
\hline No. Aluminium Can pipes & 15 \\
\hline
\end{tabular}

\section{Thermal Energy Storage with Heat Pipe Physical} model:

1) Latent heat thermal energy storage (LHTES): LHTES involves heating a material until it experiences a phase change, which can be from solid to liquid or from liquid to gas; when the material reaches its phase change temperature it absorbs a large amount of heat in order to carry out the transformation, known as the latent heat of fusion or vaporization depending on the case, and in this manner the energy is stored.

The following graph further explains the storage mechanism; as a solid material is heated its temperature begins to increase in direct proportion to the received energy until it reaches the melting temperature. Beyond this point, the energy delivered to the material ceases to raise the temperature, and is used instead to perform the transition from solid to liquid (latent heat), that is, the material stores isothermally the thermal energy received; once the transformation is complete and the material is wholly in the liquid state, the temperature begins to increase again as it receives a heat input until it reaches the vaporization point where the occurred in the first phase change is repeated. The heating process works the same way for cooling, which means that it is possible to extract the stored energy as latent heat at a constant temperature As can be seen it is impossible to exclusively store latent heat, as to reach the phase change point the material had to undergo a temperature increase which represents storage of sensible heat. The storage capacity of an LHS system can be represented by the following expression

$\mathrm{Q}=\int_{T i}^{T m} C p d T+\operatorname{mam} \Delta h m+\int_{T m}^{T f} m C p d T \ldots 1$

$\mathrm{Q}=\mathrm{m}\{\mathrm{Csp}[\mathrm{Tm}-\mathrm{Ti}]+\mathrm{am} \Delta \mathrm{hm}+\mathrm{Clp}[\mathrm{Tf}-\mathrm{Tm}]\} \quad \ldots 2$

The first term of the equation represents the sensible heat stored by the material temperature increase from its initial temperature to the phase change temperature, the second term represents the energy stored by the latent heat of the material during the phase change, the amount of energy stored depends on the amount of material, the specific latent heat and the fraction of the material that has experienced a transformation.

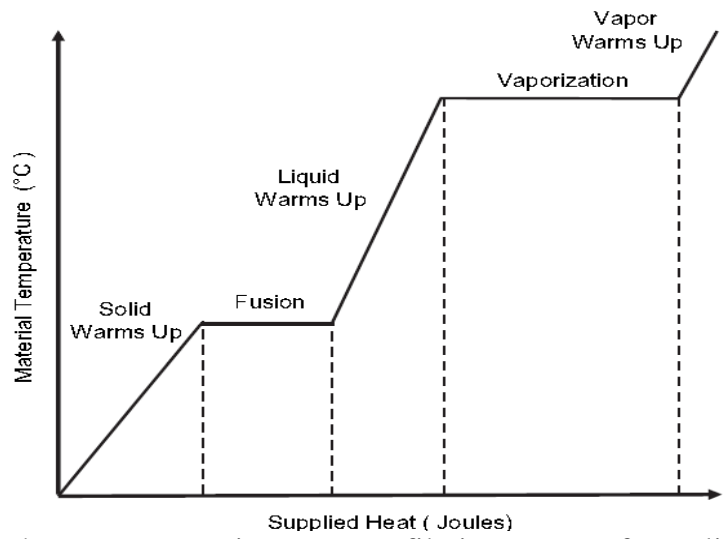

Fig.4. Temperature increase profile in respect of supplied heat. 


\section{IAR JSET}

Vol. 4, Special Issue 1, January 2017

If the material is further heated after the phase change a three sections; these three sections are filling with PCM as third term appears in the equation to account again for Paraffin Wax.

sensible heat storage.

2) Heat Pipe: The heat pipe is a vapour-liquid phase change device that transfers heat from evaporator to the condenser using capillary forces generated by a wick or porous material and a working fluid. Capillary-driven twophase systems offer significant advantages over traditional single-phase systems. The best known capillary-driven two phase system is the heat pipe, where a schematic of conventional heat pipe is shown in Fig. 3. Heat pipes are passive devices that transport heat over relatively long distances via the latent heat of vaporization of a working fluid. As shown, a heat pipe generally has three sections: an evaporator section, an adiabatic section, and a condenser section. Due to the two-phase characteristic, the heat pipe is deal for transferring heat over long distances with a very small temperature drop and for creating a nearly isothermal surface for temperature stabilization. Given the wide range of operating temperatures for working fluids, the high efficiencies, the low relative weights, and the absence of external pumps in heat pipes, these systems are seen as attractive options in a wide range of heat transfer applications.

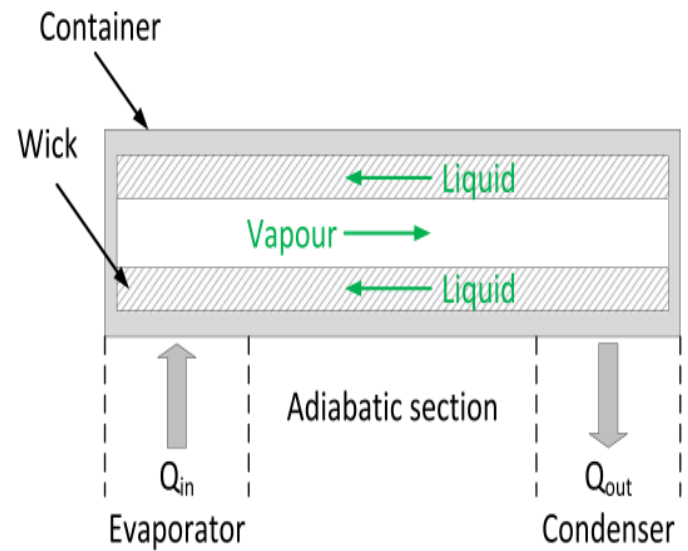

Fig.5. Working Principle of Heat Pipe.

Table no 2: Speciation of Heat pipe.

\begin{tabular}{|l|l|}
\hline Evaporator Length Le & $0.45[\mathrm{M}]$ \\
\hline Adiabatic Length Lad & $0.15[\mathrm{M}]$ \\
\hline Condenser Length Lc & $0.20[\mathrm{M}]$ \\
\hline Total Length Lt & $0.8[\mathrm{M}]$ \\
\hline Effective Length Lef & $0.65[\mathrm{M}]$ \\
\hline Inner Radius Ri & $0.001[\mathrm{M}]$ \\
\hline Thermal Conductivity Am & $385[\mathrm{~W} . \mathrm{M}-1 . \mathrm{K}-1]$ \\
\hline Vapor Core Radius Rv & $0.00065[\mathrm{M}]$ \\
\hline Max Heat Transfer Capacity & $300 \mathrm{~W}$ \\
\hline C/s Area of Wick Structure Ak & $0.0000168[\mathrm{M} 2]$ \\
\hline
\end{tabular}

3) Physical model: Thermal energy storage (TES) unit is made up of Heat pipe with fins. TES unit is divided into

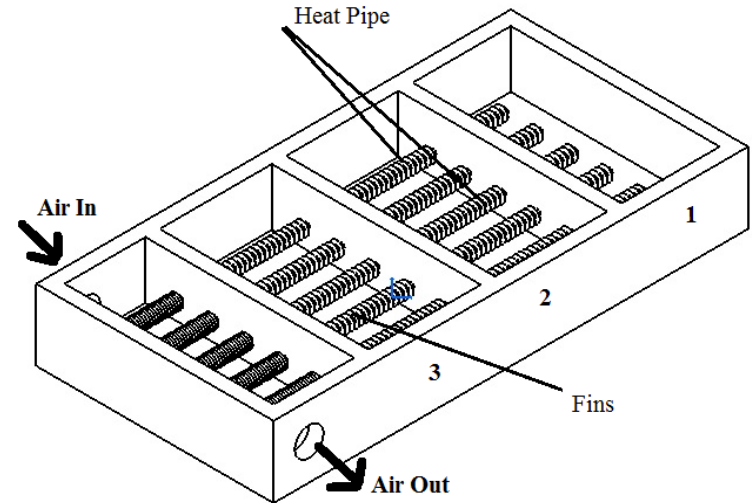

Fig 6: Schematics of LHTES unit; Five Heat pipe and Fin

During day time direct solar radiation is incident on TES unit i.e. charging time of TES unit. The energy will be stored in the TES unit, that energy is used during night time. The flow of energy from $1^{\text {st }}$ section to another end and that energy is carried out to TES unit by air.

4) Drying Chamber: Design of solar drying chamber is most important part of the solar drying system because air flow through chamber also depends on design. Drying chambers with a flat bottom, vertical box type drying chambers. Drying Systems should be designed to be the most efficient and economical. It is rectangular shaped drying chamber with dimension of $150 \times 50 \mathrm{cmX} 60 \mathrm{~cm}$. Drying chamber take hot air from the Solar Air Heater through a pipe and removes the humidity or moisture content from the product and dry the product. Hot air leaves in atmosphere through solar chimney.

Air Mass Flow Rate: $m=\rho$ Aout V

Where $\mathrm{V}$ is average outflow air velocity in channels, Aout is outflow duct area and $\rho$ is the outflow air density at outflow temperature.

The thermal efficiency of the solar collectors $(\eta)$ is defined as the ratio between the energy gain and the solar radiation incident on the collector plane:

$$
\eta=\mathrm{m} . \mathrm{Cp} \Delta \mathrm{T} / \mathrm{I} \text {.At }
$$

where $\mathrm{I}$ is solar radiation incident to the outer plate $\mathrm{W} / \mathrm{m} 2$ , At is plates area, $\mathrm{Cp}$ is specific heat capacity of air $\left[\mathrm{kJ} / \mathrm{kg}^{\circ} \mathrm{c}\right]$ at air mean temperature, $\Delta \mathrm{T}$ is temperature difference between inlet and outlet airflow $\left({ }^{\circ} \mathrm{C}\right)$. The heat loss calculations for solar collector. The solar thermal efficiency depends essentially on thermal losses from outer surfaces of the collector.

\section{RESULTS AND DISCUSSION}

The graph of figure7 is plotted between Outlet air temperatures vs. time. Graph shows hourly variation of Outlet air temperatures, as the day progresses solar intensity increases with maximum at noon. This reading for natural convection. 
IARJSET

International Advanced Research Journal in Science, Engineering and Technology

National Conference on Design, Manufacturing, Energy \& Thermal Engineering (NCDMETE-2017) AGTI's Dr. Daulatrao Aher College Engineering, Vidyanagar Extension, Karad

Vol. 4, Special Issue 1, January 2017

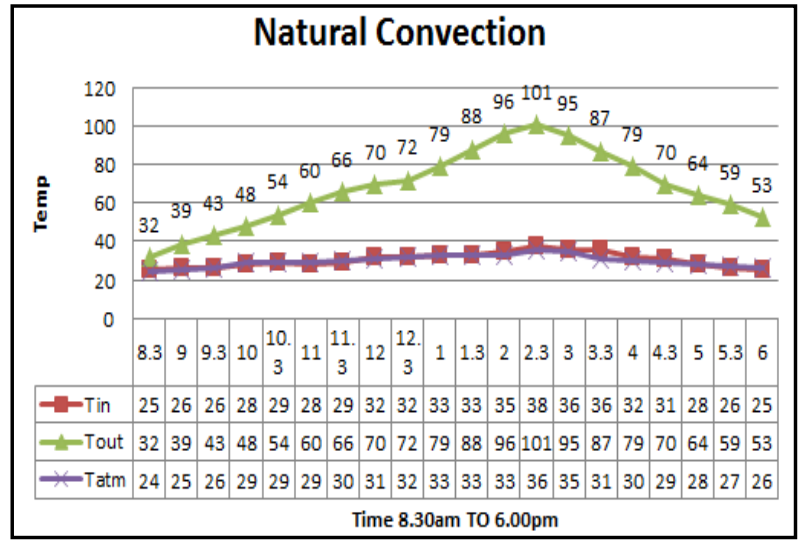

Fig 7: Outlet air temperatures vs. time

The graph of figure8, 9, and 10 is shows relation between Outlet air temperatures vs. time for forced convection at 2 $\mathrm{m} / \mathrm{sec}$. As air velocity increases outlet temperature decrease at noon and efficiency of collector also decrease. For air velocity $2 \mathrm{~m} / \mathrm{sec} \max$ temperature is $92^{\circ} \mathrm{C}$.

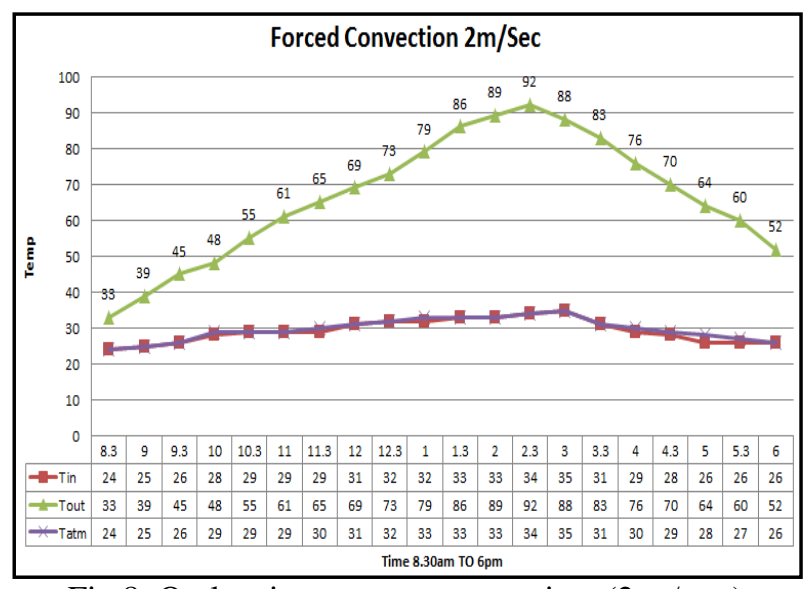

Fig 8: Outlet air temperatures vs. time $(2 \mathrm{~m} / \mathrm{sec})$

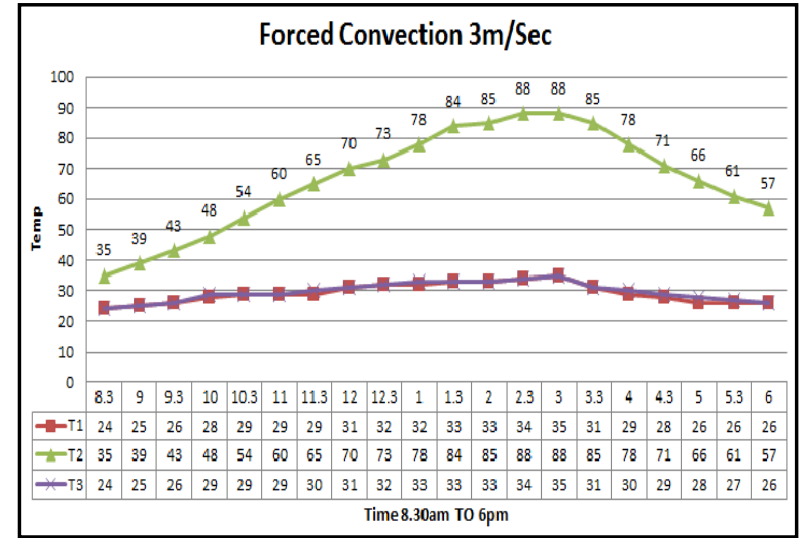

Fig 9: Outlet air temperatures vs. time $(3 \mathrm{~m} / \mathrm{sec})$

For air velocity $3 \mathrm{~m} / \mathrm{sec}$ max temperature is $88^{\circ} \mathrm{C}$ and for air velocity $4 \mathrm{~m} / \mathrm{sec} \max$ temperature is $85^{\circ} \mathrm{C}$. Temperature difference between inlet air temperature and outlet temperature is decreases as mass flow rate increases. Maximum temperature gets at natural convection.

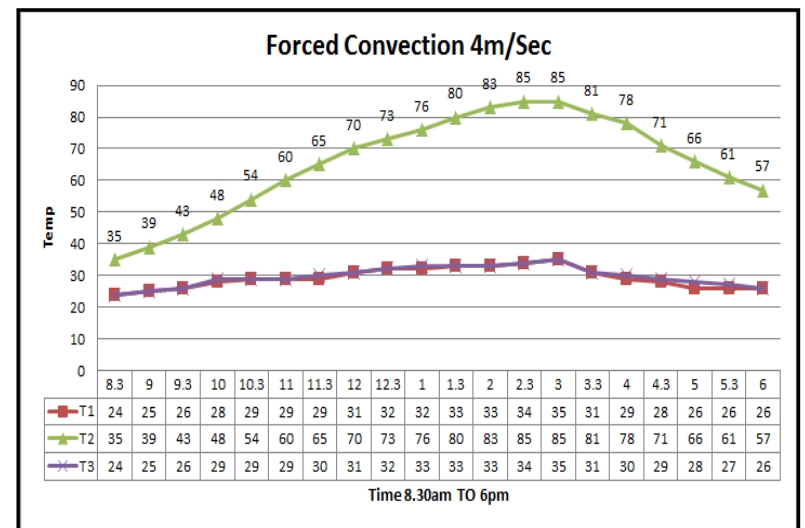

Fig 10: Outlet air temperatures vs. time $(4 \mathrm{~m} / \mathrm{sec})$

The graph of figure11 is plotted between Outlet air temperatures vs. night time. This graph of Thermal Energy Storage unit, when air flow through TES unit the max temperature at $7 \mathrm{pm}$ is $53^{\circ} \mathrm{C}$ during night time for natural convection.

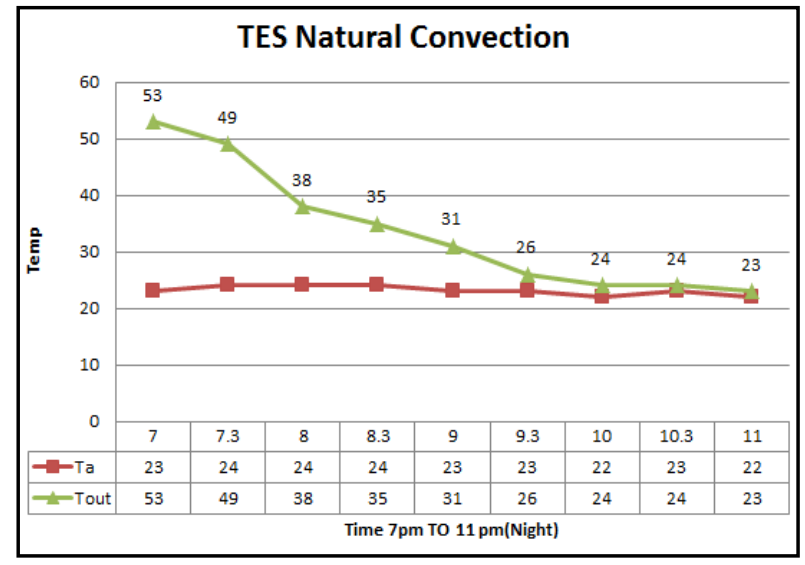

Fig 11: Outlet air temperatures vs. night time

Slowly discharging the TES unit and outlet temperature also decreases. TES unit is working for 3-4 hrs. during night time.

The graph of figure12, 13, and 14 shows as mass flow increases discharging rate of TES unit increases. In case 2 $\mathrm{m} / \mathrm{sec}$ max time working of TES unit.

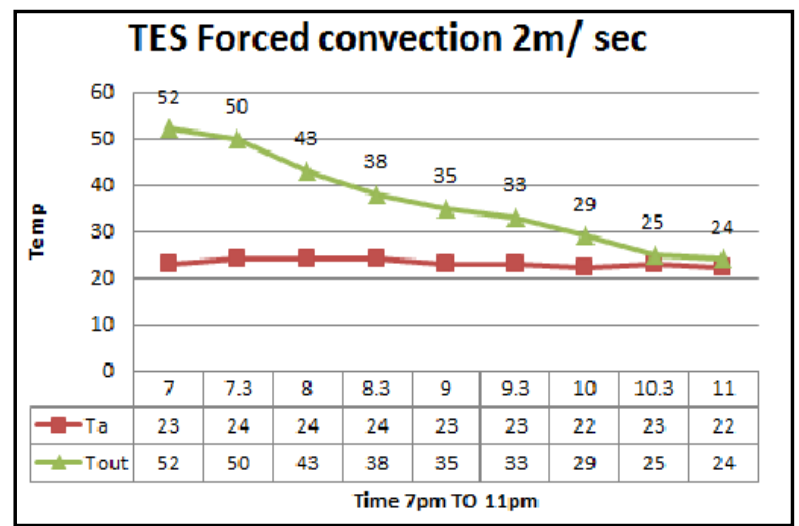

Fig 12: Outlet air temperatures vs. night time 
IARJSET

Vol. 4, Special Issue 1, January 2017

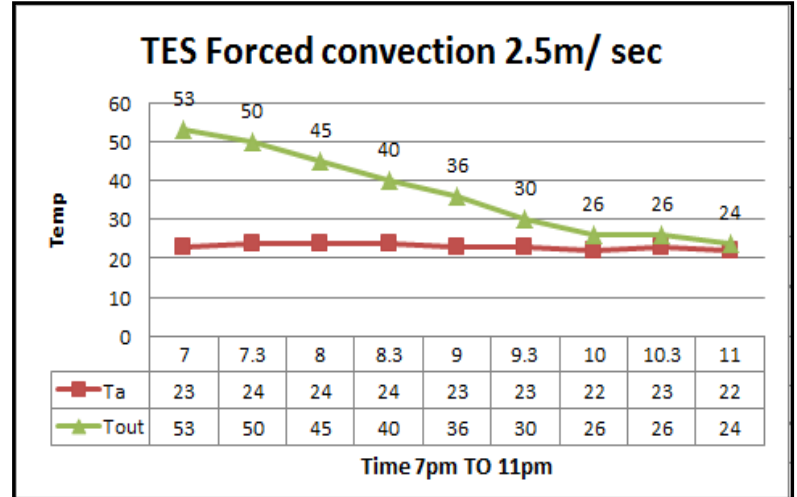

Fig 13: Outlet air temperatures vs. night time

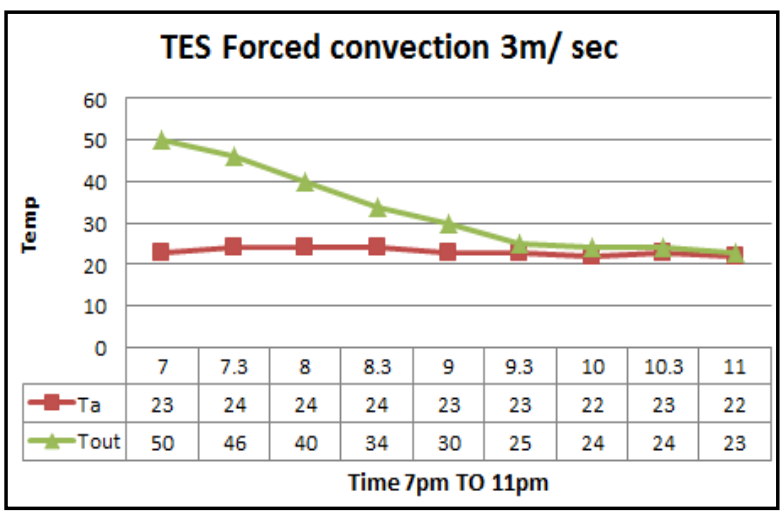

Fig 14: Outlet air temperatures vs. night time

The graph of figure 15 shows the sections of TES unit as referring the figure 6 .

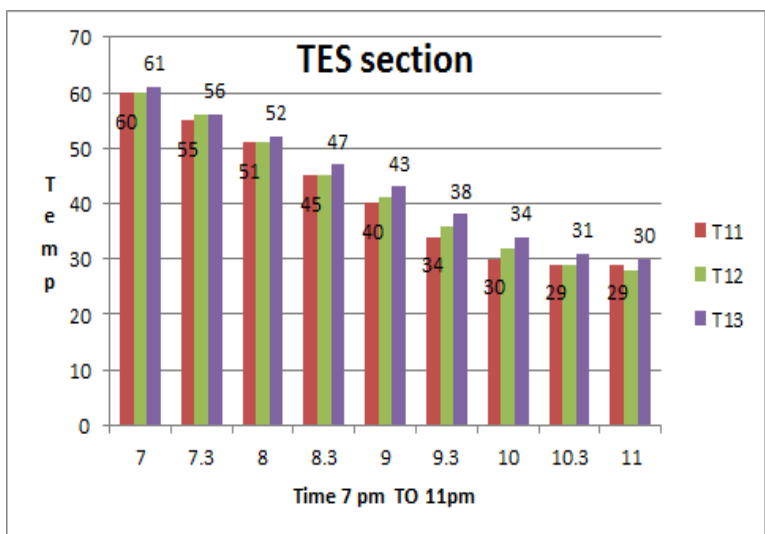

Fig 15: Outlet air temperatures vs. time

T11, T12 and T13 show the temperature in the section of TES unit 1,2 and 3. Result shows that the adiabatic section of heat pipe is transfer the heat slowly and discharging rate of section 3 is less than section 1 and 2 . Fin is also enhancing the performance of TES unit.

\section{CONCLUSION}

- If we vary the velocity of air then efficiency decreases as velocity air increases.
- If $\Delta \mathrm{T}$ increases then efficiency increases.

- If solar intensity increases efficiency first increase and then decreases.

- Because of TES unit total no. of hours of drying increases so productivity increases.

\section{ACKNOWLEDGMENT}

The Authors would like to thank PCCOE Pune. For his valuable support for developing Solar air Dryer, Thanks to Prof. S. P. Salve for his valuable contribution in developing the Solar air Dryer.

\section{REFERENCES}

[1] Bruno Cárdenas n, NoelLeón 'High temperature latent heat thermal energy storage: Phase change materials, design considerations and performance enhancement techniques' Renewable and Sustainable Energy Reviews 27(2013)724-737.

[2] Saeed Tiari, Songgang Qiu, Mahboobe Mahdavi 'Numerical study of finned heat pipe-assisted thermal energy storage system with high temperature phase change material' Energy Conversion and Management 89 (2015) 833-842.

[3] Christopher W. Robak, Theodore L. Bergman, Amir Faghri 'Enhancement of latent heat energy storage using embedded heat pipes' International Journal of Heat and Mass Transfer 54 (2011) 3476-3484.

[4] S. Jegadheeswaran, S.D. Pohekar, 'Performance enhancement in latent heat thermal storage system: a review', Renew. Sust. Energ. Rev. 13 (9) (2009) 2225-2244.

[5] R. Velraj, R.V. Seeniraj, B. Hafner, C. Faber, K. Schwarzer, 'Heat transfer enhancement in a latent heat storage system', Sol. Energy 65 (3) (1999) 171-180.

[6] J.R. Balikowski, J.C. Mollendorf, 'Performance of phase change materials in a horizontal annulus of a double-pipe heat exchanger in a water circulation loop', J. Heat Transfer 129 (3) (2007) 265-272.

[7] E.M. Sparrow, E.D. Larson, J.W. Ramsey, Freezing on a finned tube for either conduction-controlled or natural-convectioncontrolled heat transfer', Int. J. Heat Mass Transfer 24 (2) (1981) 273-283.

[8] F. Agyenim, P. Eames, M. Smyth, 'Heat transfer enhancement in medium temperature thermal energy storage system using a multitude heat transfer array', Renew. Energy 35 (1) (2010) 198207.

[9] A. Faghri, US Patent No. 5000252, 1991.

[10] A. Faghri, US Patent No. 4976308, 1990.

[11] W.-S. Lee, B.-R. Chen, S.-L. Chen, 'Latent heat storage in a twophase thermosyphon solar water heater', J. Sol. Energy. Eng. 128 (1) (2006) 69-76.

[12] Z. Liu, Z. Wang, C. Ma, 'An experimental study on heat transfer characteristics of heat pipe heat exchanger with latent heat storage. Part I: charging only and discharging only modes', Energy. Convers. Manage. 47 (7) (2005) 944-966.

[13] H. Shabgard, T.L. Bergman, N. Sharifi, A. Faghri, 'High temperature latent heat thermal energy storage using heat pipes', Int. J. Heat Mass Transfer 53 (15-16) (2010) 2979-2988. 